\title{
The Use of Complementary and Alternative Medicine by Korean Breast Cancer Women: Is It Associated with Severity of Symptoms?
}

\author{
Jung Hye Hwang, ${ }^{1,2}$ Woon-Yong Kim, ${ }^{2}$ Mansoor Ahmed, ${ }^{2,3}$ Soojeung Choi, ${ }^{2,3}$ Jiwoo Kim,,3 \\ and Dong Woon Han ${ }^{2,3}$ \\ ${ }^{1}$ Department of Obstetrics and Gynecology, Hanyang University, College of Medicine, 222 Wangsimni-ro, Seongdong-gu, Seoul 04763, \\ Republic of Korea \\ ${ }^{2}$ Institute of Health Services Management, Hanyang University, 222 Wangsimni-ro, Seongdong-gu, Seoul 04763, Republic of Korea \\ ${ }^{3}$ Department of Global Health and Department of Preventive Medicine, Hanyang University, College of Medicine, 222 Wangsimni-ro, \\ Seongdong-gu, Seoul 04763, Republic of Korea
}

Correspondence should be addressed to Dong Woon Han; dwhan@hanyang.ac.kr

Received 3 July 2015; Accepted 22 November 2015

Academic Editor: Pradeep Visen

Copyright (C) 2015 Jung Hye Hwang et al. This is an open access article distributed under the Creative Commons Attribution License, which permits unrestricted use, distribution, and reproduction in any medium, provided the original work is properly cited.

\begin{abstract}
Background. Use of complementary and alternative medicine (CAM) among patients with breast cancer could be associated with severity of the cancer symptoms experienced, but there is little evidence to prove this. This study tried to investigate any difference in the severity of breast cancer symptoms between CAM users and nonusers. Methods. The study followed cross-sectional design using structured survey questionnaire. Survey participants were recruited from four different healthcare settings in Seoul, South Korea. The survey instrument comprised 39 items including questions on demographics, use of CAM, and six main symptoms associated with breast cancer and cancer treatment. Results. Out of 288 participants, $67 \%$ stated using one or more modalities of CAM. Age, education, and time duration since diagnosis of cancer were significantly associated with use of CAM. About $90 \%$ of the CAM users experienced side effects of cancer treatment. CAM users reported more severe anxiety and skin/hair changes than nonusers. Conclusions. CAM was used by those breast cancer patients who experience more severe symptoms to alleviate the conditions associated with breast cancer and cancer treatment. Our findings revealed motivation behind the CAM use, which has profound implications for clinicians to recognize patient-perceived needs.
\end{abstract}

\section{Introduction}

Breast cancer is a chronic disease associated with severe physical and emotional burden [1]. Results of a five-year observational cohort study in the UK showed presence of depression, anxiety, or both in nearly $50 \%$ of the women with breast cancer [2], and pain, fatigue, anorexia, and skin changes are common over the course of the disease and its treatment [3]. For managing these cancer-associated symptoms, there are few approved standard guidelines; therefore, as compared to patients with other cancers, use of complementary and alternative medicine (CAM) is most common among breast cancer women [4]. Such increase in popularity of CAM might be due to the breast cancer patients' dissatisfaction with conventional therapies so they could integrate it with use of CAM [5]. Furthermore, research suggests that symptom management is one of the most common reasons behind CAM use among women with breast cancer $[6,7]$. We hypothesize that use of CAM could be associated with severity of symptoms experienced by women with breast cancer. However, no conclusive research has been conducted to establish relationship between use of CAM and severity of symptoms associated with breast cancer and its treatment [8].

A number of studies have underscored high prevalence of CAM among women with breast cancer [9-12]. The variety 
of CAM therapies used and the factors related to CAM use have also been recognized by several researchers. A study reported that dietary supplements are the most preferred type of CAM used by women with breast cancer, while another study reported that meditation, herbs, and spiritual healing are the most commonly used modalities of CAM among such patients $[13,14]$. Wanchai et al. demonstrated that women with breast cancer with higher level of education, higher income level, and younger age have increased tendency to be consumers of CAM [15].

In Korea, breast cancer is the most common type of cancer among female population and the prevalence has been increasing continuously [16]. Moreover, the most recent report reveals that more than $50 \%$ of the Korean women with breast cancer experience cancer-associated anxiety and depression [17]. Few studies have focused on the use of CAM among women with breast cancer in Korea; however, they did not investigate why these women use CAM. A survey on 160 Korean women with breast cancer highlighted the CAM usage by $36 \%$ of the participants [18]. The more recent survey conducted on the breast cancer patients in Korea reported the use of CAM by $57.4 \%$ of the patients [19]. The study discussed only quality of life indicators among CAM users and nonusers [19]. To the best of our knowledge, the surveys conducted in Asian populations so far have not studied differences in the severity of symptoms associated with breast cancer and its treatment between users of CAM and nonusers. The aim of this study is to evaluate the use of CAM in the Korean women with breast cancer by investigating differences in the severity of self-reported symptoms associated with breast cancer and its treatment between users of CAM and nonusers. Additionally, the study explored CAM users' attitudes towards CAM and conventional healthcare.

\section{Methods}

2.1. Participants. The study followed cross-sectional design to investigate the CAM use among South Korean female breast cancer survivors. Structured questionnaire was used to conduct face-to-face survey for three weeks from May 31, 2012, to June 20, 2012. The subjects were Korean female breast cancer patients aged over 18 years and were invited to participate in the study when they visited outpatient department of four hospitals located in Seoul, namely, Hanyang University Seoul Hospital, Hanyang University Guri Hospital, Cheil General Hospital and Women's Healthcare Centre, and Jeongpajong Breast and Thyroid Clinic. A total of 300 subjects were invited and all of them agreed to participate in the survey. Given that 12 participants did not complete the questionnaire, data of only 288 participants were included in the final analysis.

Ethical approval for the study was obtained from the Institutional Review Board on Human Subjects Research and Ethics Committees, Hanyang University Guri Hospital. Prior to the survey, all participants provided IRB-approved written informed consent.

2.2. Data Collection. In order to conduct the survey in each of the facilities, four surveyors were trained. The survey questionnaire, developed in the Korean language, is comprised of a total of 39 items. Questions were asked on use of CAM, demographic characteristics, CAM users' attitudes towards conventional health care, sources of information, and severity of six self-reported symptoms, namely, pain, fatigue, depression, anorexia, skin and hair changes, and anxiety. Severity of each symptom was rated on a 6-point Likert scale from 0 to 5 (no symptom to most severe). All of the participants were asked to respond to questions on demographic characteristics, CAM use, and severity of symptoms, whereas questions related to attitudes, types of CAM, source of information, and communication were asked from CAM users only.

2.3. Statistical Analysis. Descriptive statistics (using number and percentage) were used to describe severity of symptoms, CAM users' attitudes, types of CAM, and sources of information. Linear logistic regression analysis was created (assuming confidence interval of 95\%) to see any association between participants' characteristics and use of CAM. In the regression model, we considered use of CAM as dependent variable whereas independent variables comprising age, religion, education, marital status, employment, household income, family history of cancer, diagnostic institution, method of diagnosis, and time since breast cancer were diagnosed. We selected significance level of $\alpha=0.05$ for all analyses. The data were analyzed using Statistical Package for Social Sciences (SPSS) v. 18.0.

\section{Results}

3.1. Demographics. Table 1 displays characteristics of 288 study subjects. In terms of characteristics, $37.2 \%$ were aged $>54$ years, $58.7 \%$ followed Western religions (Roman Catholic, Christian), $62.5 \%$ had education up to high school, $82.6 \%$ were married, $55.2 \%$ were unemployed, $63.2 \%$ had household income $<5$ million KRW, $72.9 \%$ had no family history of cancer, and $54.2 \%$ were residents of Seoul.

3.2. Utilization of CAM and Predictors. In total, 193 (67\%) participants stated utilizing one or more modalities of CAM (Table 1). Participants who were more likely to use CAM were in the age between 46 and 54 years $(39.4 \%)$ and were followers of Western religions (63.7\%), of higher school or lower education level (58.5\%), married (84.5\%), unemployed (51.3\%), with household income $<5$ million won/month (57.5\%), without family history of cancer (72\%), residents of Seoul (59.1\%), and with cancer diagnosed at facilities other than tertiary care hospitals (61.1\%), cancer detected by screening (56.5\%), and cancer diagnosed since 12-36 months (33.7\%). Logistic regression analysis revealed that age, level of education, and time since diagnosis were significantly associated with use of CAM.

3.3. Severity of Symptoms. Table 2 presents Likert scale data with full frequency distributions of the scores on severity of self-reported symptoms among CAM users and nonusers. The proportion of high severity of symptoms is relatively 
TABLE 1: Participants' characteristics according to CAM use.

\begin{tabular}{|c|c|c|c|c|c|c|c|}
\hline \multirow{2}{*}{ Characteristics } & \multicolumn{2}{|c|}{ CAM users } & \multicolumn{2}{|c|}{ Nonusers } & \multicolumn{2}{|c|}{ Total } & \multirow{2}{*}{$P$ value } \\
\hline & $N$ & $\%$ & $N$ & $\%$ & $N$ & $\%$ & \\
\hline & 193 & 67.0 & 95 & 33.0 & 288 & 100.0 & \\
\hline Age group & & & & & & & 0.003 \\
\hline$<46$ & 59 & 30.6 & 27 & 28.4 & 86 & 29.9 & \\
\hline $46-54$ & 76 & 39.4 & 19 & 20.0 & 95 & 33.0 & \\
\hline$>54$ & 58 & 30.1 & 49 & 51.6 & 107 & 37.2 & \\
\hline Religion & & & & & & & 0.122 \\
\hline Western & 123 & 63.7 & 46 & 48.4 & 169 & 58.7 & \\
\hline Eastern & 70 & 36.3 & 49 & 51.6 & 119 & 41.3 & \\
\hline Education & & & & & & & 0.027 \\
\hline$\leq$ High school & 113 & 58.5 & 67 & 70.5 & 180 & 62.5 & \\
\hline$\geq$ University & 80 & 41.5 & 28 & 29.5 & 108 & 37.5 & \\
\hline Marital status & & & & & & & 0.455 \\
\hline Single & 30 & 15.5 & 20 & 21.1 & 50 & 17.4 & \\
\hline Married & 163 & 84.5 & 75 & 78.9 & 238 & 82.6 & \\
\hline Employed & & & & & & & 0.320 \\
\hline No & 99 & 51.3 & 60 & 63.2 & 159 & 55.2 & \\
\hline Yes & 94 & 48.7 & 35 & 36.8 & 129 & 44.8 & \\
\hline Household income & & & & & & & 0.797 \\
\hline$<5$ million won/month & 111 & 57.5 & 71 & 74.7 & 182 & 63.2 & \\
\hline$\geq 5$ million won/month & 82 & 42.5 & 24 & 25.3 & 106 & 36.8 & \\
\hline Family history of cancer & & & & & & & 0.465 \\
\hline No & 139 & 72.0 & 71 & 74.7 & 210 & 72.9 & \\
\hline Yes & 54 & 28.0 & 24 & 25.3 & 78 & 27.1 & \\
\hline Residence & & & & & & & 0.537 \\
\hline Seoul & 114 & 59.1 & 42 & 44.2 & 156 & 54.2 & \\
\hline Elsewhere & 79 & 40.9 & 53 & 55.8 & 132 & 45.8 & \\
\hline Where diagnosed & & & & & & & 0.119 \\
\hline Tertiary care hospitals & 75 & 38.9 & 45 & 47.4 & 120 & 41.7 & \\
\hline Other & 118 & 61.1 & 50 & 52.6 & 168 & 58.3 & \\
\hline Detected by & & & & & & & 0.616 \\
\hline Screening & 109 & 56.5 & 65 & 68.4 & 174 & 60.4 & \\
\hline Symptoms & 84 & 43.5 & 30 & 31.6 & 114 & 39.6 & \\
\hline Months since diagnosis & & & & & & & 0.036 \\
\hline$<12$ & 47 & 24.4 & 32 & 33.7 & 79 & 27.4 & \\
\hline $12-36$ & 65 & 33.7 & 26 & 27.4 & 91 & 31.6 & \\
\hline $37-60$ & 38 & 19.7 & 18 & 18.9 & 56 & 19.4 & \\
\hline$>60$ & 43 & 22.3 & 19 & 20.0 & 62 & 21.5 & \\
\hline
\end{tabular}

${ }^{*} 5$ million Korean won (KRW) was about 4,500 US dollars at the time of survey.

TABLE 2: Severity of self-reported symptoms between CAM users (193) and nonusers (95): N (\%).

\begin{tabular}{lcccccccccccc}
\hline \multirow{2}{*}{ Score } & \multicolumn{2}{c}{ Pain } & \multicolumn{2}{c}{ Fatigue } & \multicolumn{2}{c}{ Depression } & \multicolumn{2}{c}{ Anorexia } & \multicolumn{3}{c}{ Skin/hair changes } & \multicolumn{2}{c}{ Anxiety } \\
& CAM user & Nonuser & CAM & Non & CAM & Non & CAM & Non & CAM & Non & CAM & Non \\
\hline 0 & $47(24.4)$ & $24(25.3)$ & $19(9.8)$ & $17(17.9)$ & $28(14.5)$ & $21(22.1)$ & $22(11.4)$ & $13(13.7)$ & $26(13.5)$ & $20(21.1)$ & $21(10.9)$ & $13(13.7)$ \\
1 & $52(26.9)$ & $31(32.6)$ & $49(25.4)$ & $35(36.9)$ & $47(24.4)$ & $32(33.7)$ & $41(21.2)$ & $28(29.5)$ & $46(23.8)$ & $36(37.9)$ & $42(21.8)$ & $31(32.6)$ \\
2 & $17(8.8)$ & $8(8.4)$ & $13(6.7)$ & $1(1.1)$ & $11(5.7)$ & $3(3.2)$ & $13(6.7)$ & $2(2.1)$ & $15(7.8)$ & $3(3.2)$ & $17(8.8)$ & $8(8.4)$ \\
3 & $33(17.1)$ & $12(12.6)$ & $49(25.4)$ & $19(20)$ & $50(25.9)$ & $17(17.9)$ & $40(20.7)$ & $20(21.1)$ & $30(15.5)$ & $15(15.8)$ & $35(18.1)$ & $21(22.1)$ \\
4 & $19(9.8)$ & $11(11.6)$ & $35(18.1)$ & $11(11.6)$ & $30(15.5)$ & $11(11.6)$ & $38(19.7)$ & $15(15.8)$ & $33(17.1)$ & $9(9.5)$ & $41(21.2)$ & $10(10.5)$ \\
5 & $25(13.0)$ & $9(9.5)$ & $28(14.5)$ & $12(12.6)$ & $27(14)$ & $11(11.6)$ & $39(20.2)$ & $17(17.9)$ & $43(22.3)$ & $12(12.6)$ & $37(19.2)$ & $12(12.6)$ \\
\hline
\end{tabular}


TABLE 3: CAM users' attitudes towards CAM.

\begin{tabular}{lcc}
\hline Category & $N$ & $\%$ \\
\hline Reason for using CAM & & \\
For cancer treatment & 14 & 7.3 \\
To prevent progress of disease & 76 & 39.4 \\
To mitigate symptoms & 62 & 32.1 \\
To enhance immune system & 37 & 19.2 \\
Other & 4 & 2.1 \\
Reduces overall costs & & \\
No & 126 & 65.3 \\
Yes & 67 & 34.7 \\
Reduces healthcare utilization & & \\
No & 131 & 67.9 \\
Yes & 62 & 32.1 \\
CAM recommended by & & \\
Myself & 78 & 40.4 \\
Family & 59 & 30.6 \\
Breast cancer patients & 20 & 10.4 \\
Other relatives or friends & 17 & 8.8 \\
My healthcare provider & 15 & 7.7 \\
Other & 4 & 2.1 \\
CAM helps in treatment of cancer & & \\
No & 99 & 51.3 \\
Yes & 94.7 \\
Plans to continue using CAM & & \\
No & 72 & \\
Yes & & \\
\hline
\end{tabular}

higher among CAM users than among the nonusers, especially in the case of anxiety and skin/hair changes. Similarly, proportion of participants without symptoms is relatively higher among nonusers than among CAM users for all symptoms.

3.4. Attitudes towards CAM. Table 3 shows information on CAM users' attitudes and practices regarding CAM. Out of 193 CAM users, 39.4\% believed that CAM prevents progression of breast cancer and promotes health and 32.1\% used it to mitigate symptoms and $19.2 \%$ used it to enhance the immune system. Moreover, $65.3 \%$ did not believe that CAM reduces costs for the treatment of breast cancer and only $32.1 \%$ believed that CAM reduces overall health care utilization. When asked who recommended them to use CAM, $40.4 \%$ responded that it was their own decision, $30.6 \%$ were advised by their family, and only $8.8 \%$ were suggested by their respective healthcare provider whereas only $48.7 \%$ believed that CAM helps in the treatment of breast cancer and $62.7 \%$ had plans to continue using any of the CAM therapies.

3.5. Attitudes towards Conventional Health Care. CAM users' attitudes towards conventional health care are illustrated in Table 4. Out of 193 CAM users, $61.7 \%$ did not disclose to their healthcare providers. The reasons for not doing so were given as follows: there is no need to discuss (63.9\%) and healthcare
TABLE 4: CAM users' attitudes towards conventional health care.

\begin{tabular}{lcc}
\hline Category & $N$ & $\%$ \\
\hline Disclosure of CAM use to healthcare provider & & \\
$\quad$ Yes & 74 & 38.3 \\
No & 119 & 61.7 \\
Reason for nondisclosure & 36 & 30.3 \\
$\quad$ Healthcare provider may dislike it & 76 & 63.9 \\
There is no need to disclose & 0 & 0 \\
I am not open-minded type & 1 & 0.8 \\
Healthcare provider does not know about CAM & 6 & 5.0 \\
Other & & \\
Any side effects of cancer therapy & 173 & 89.6 \\
Yes & 20 & 10.4 \\
No &
\end{tabular}

TABLE 5: Modalities of CAM used.

\begin{tabular}{|c|c|c|}
\hline CAM & $N$ & $\%$ \\
\hline \multicolumn{3}{|l|}{ Dietary, nutritional therapy } \\
\hline Mushrooms & 90 & 46.6 \\
\hline Ginseng & 103 & 53.4 \\
\hline Beans & 84 & 43.5 \\
\hline Kale, Onion juice & 54 & 28.0 \\
\hline \multicolumn{3}{|l|}{ Biological supplements } \\
\hline Vitamins & 78 & 40.4 \\
\hline Medicinal herbs (aloe, dandelion) & 22 & 11.4 \\
\hline Supplements for blood circulation & 17 & 8.8 \\
\hline Shark cartilage, Chitosan & 10 & 5.2 \\
\hline \multicolumn{3}{|l|}{ Mind-body interventions } \\
\hline Prayer, Meditation, Zen & 66 & 34.2 \\
\hline Exercise, Yoga & 104 & 53.9 \\
\hline Psychotherapy & 14 & 7.3 \\
\hline Breathing & 4 & 2.1 \\
\hline \multicolumn{3}{|l|}{ Manipulative and body-based therapies } \\
\hline Massage & 39 & 20.2 \\
\hline Sujichim (Korean hand acupuncture) & 1 & 0.5 \\
\hline Acupressure & 6 & 3.1 \\
\hline Chiropractic (Chuna therapy) & 2 & 1.0 \\
\hline \multicolumn{3}{|l|}{ Alternative medicine } \\
\hline Acupuncture & 43 & 22.3 \\
\hline Traditional Korean Herbal Medicine & 45 & 23.3 \\
\hline Moxibustion and Cupping & 14 & 7.3 \\
\hline Physiotherapy & 0 & 0 \\
\hline Other & 3 & 1.6 \\
\hline
\end{tabular}

provider may dislike it (30.3\%). Eighty-nine percent of the CAM users in our study had experienced one or more side effects of the conventional therapy for breast cancer.

3.6. Modalities of CAM Use. Modalities of CAM used by study participants are shown in Table 5 . The most common types of CAM were exercise and yoga $(53.9 \%)$, ginseng (53.4\%), mushrooms (46.6\%), beans (43.5\%), multivitamins (40.4\%), and prayer, meditation, and Zen (34.2\%). In aggregate, dietary and nutritional therapies were most popularly 
consumed, followed by mind-body interventions, alternative medicine, and biological supplements. Massage was most popularly used (20.2\%) among manipulative and body-based therapies. While among alternative medicine therapies, Traditional Korean Herbal Medicine (23.3\%) and acupuncture $(22.3 \%)$ were most commonly used by the study participants.

\section{Discussion}

This study reports the recent trend of CAM use among breast cancer survivors in South Korea. Results of our study show high prevalence of CAM utilization by $67 \%$ of the participants, which is consistent with previous studies $[15,20$, 21]. However, this rate is slightly lower when compared to use of CAM among general population in Korea [22]. Consistent with previous studies, likely predictors of CAM use included age, level of education, and time since diagnosis of breast cancer $[10,15,23]$.

Patterns of CAM modalities used among the study participants reflect their sociocultural background as ginseng was the most popular among nutritional therapies (53.4\%), whereas the previous Korean study reported its consumption as 33.6\% [19]. Overall, dietary and nutritional therapies were the most commonly consumed category of CAM, consistent with the study conducted by Fasching et al. [24]. We also found that $38.3 \%$ of the CAM users, at some point, discussed CAM use with their healthcare provider. Previous Korean studies reported this number at $20 \%$ and $29.6 \%$, respectively $[18,19]$. These numbers suggest increase in disclosure of CAM use to healthcare providers in the country.

Our results show that $90 \%$ of the CAM users experienced side effects of conventional therapy for cancer, which is supported by previous studies $[25,26]$. The breast cancer patients used CAM to complement conventional medical treatment, which is further confirmed by our results where majority of the CAM users believed that using CAM reduces neither overall costs of care nor healthcare utilization. Thus, as our results illustrate, participants used CAM mainly to prevent progress of disease and promote health, which is similar to findings from previous studies conducted in Korea and Malaysia [19, 27]. Another major reason for using CAM was to alleviate symptoms and to enhance immune systems, which is similar to previous research $[10,28]$. In order to see any difference between CAM users and nonusers, we compared the two groups with relation to severity of selfreported symptoms.

Based on the literature review and our clinical experience $[2,3,17]$, we selected six symptoms for investigation: pain, fatigue, depression, anorexia, anxiety, and skin and hair changes. These symptoms can seriously affect breast cancer patients' quality of life, which they experience over the course of disease and its treatment $[29,30]$. Our study found significant difference in the severity of fatigue, depression, anxiety, and skin and hair changes between CAM users and nonusers. Our results imply that CAM is used by those breast cancer patients who experience more severe symptoms. Moreover, these findings are in agreement with other results of this study where symptom management is one of the major reasons for CAM use. Previous studies also show that breast cancer patients use CAM to alleviate their symptoms [28, 31]. A study conducted in the UK found that breast cancer patients undergoing radiotherapy believed that CAM would mitigate their fatigue and skin changes [32]. About 54\% of CAM users in our study were using yoga as complementary therapy. There is strong evidence of yoga therapy improving fatigue in breast cancer survivors [33]. Moreover, yoga therapy can also mitigate anxiety and other symptoms among breast cancer outpatients undergoing conventional radiotherapy and chemotherapy [34] whereas a study conducted in the United States established relationship between restorative yoga and self-reported emotional symptoms and fatigue among breast cancer patients [35]. More than 53\% of the CAM users in our sample used ginseng, which is commonly used for symptoms associated with breast cancer in Asian countries [36].

Our study has produced important findings regarding the motivation behind use of CAM among breast cancer patients. Patients, who experienced more severe symptoms, might have wanted to alleviate them via using CAM, whereas patients with milder symptoms did not use CAM. Results of the study have significant implications for clinical oncology as there is evidence of side effects from CAM use [37]. Furthermore, results of the study may enable oncologists to identify breast cancer patients' needs and expectations which are otherwise difficult in the absence of strong evidence supporting the effectiveness of CAM use in such patients [38]. We recommend that oncologists should be aware of the extent to which breast cancer patients use CAM and reasons for its usage. Moreover, oncologists should initiate the communication with their patients especially those who experience more severe symptoms as our results show that a large number of patients do not disclose their use of CAM. Findings of our study have given more insight into the trend of using CAM among breast cancer patients. Further studies are suggested using larger samples in different settings to more investigate the relationship between CAM use and symptoms associated with breast cancer and its treatment.

\section{Conclusions}

CAM is used by breast cancer patients who experience more severe symptoms associated with breast cancer and its treatment to alleviate the symptoms. Patients' perceptions and understanding of their illness, and health benefits from CAM use, are an evolving process that may have an influence on quality of life and health behavior choices. It remains to be discovered whether this motivation behind the use of CAM is in line with true medical benefit. As new information about CAM becomes available, it will be important to develop and provide education programs for health professionals and to increase awareness among patients.

\section{Conflict of Interests}

The authors declare that there is no conflict of interests regarding the publication of this paper. 


\section{Authors' Contribution}

Dong Woon Han was responsible for conception and design and analysis and interpretation of the data and drafted the paper. Jung Hye Hwang and Mansoor Ahmed provided feedback in each phase of the study and helped draft the paper and critically revised the paper. Woon-Yong Kim, Soojeung Choi, and Jiwoo Kim participated in the study design for collection of supplemental data and were involved in participants' recruitment. All authors read and approved the final paper.

\section{Acknowledgment}

The authors would like to express their sincere gratitude to all the interviewees for their hospitality and their willingness to share their experience with them.

\section{References}

[1] A. R. Link, M. D. Gammon, J. S. Jacobson et al., "Use of selfcare and practitioner-based forms of complementary and alternative medicine before and after a diagnosis of breast cancer," Evidence-Based Complementary and Alternative Medicine, vol. 2013, Article ID 301549, 16 pages, 2013.

[2] C. Burgess, V. Cornelius, S. Love, J. Graham, M. Richards, and A. Ramirez, "Depression and anxiety in women with early breast cancer: five year observational cohort study," British Medical Journal, vol. 330, no. 7493, pp. 702-700, 2005.

[3] S. M. Dy, K. A. Lorenz, A. Naeim, H. Sanati, A. Walling, and S. M. Asch, "Evidence-based recommendations for cancer fatigue, anorexia, depression, and dyspnea," Journal of Clinical Oncology, vol. 26, no. 23, pp. 3886-3895, 2008.

[4] C. M. Velicer and C. M. Ulrich, "Vitamin and mineral supplement use among US adults after cancer diagnosis: a systematic review," Journal of Clinical Oncology, vol. 26, no. 4, pp. 665-673, 2008.

[5] J. S. McLay, D. Stewart, J. George, C. Rore, and S. D. Heys, "Complementary and alternative medicines use by Scottish women with breast cancer. What, why and the potential for drug interactions?" European Journal of Clinical Pharmacology, vol. 68, no. 5, pp. 811-819, 2012.

[6] H. Boon, J. B. Brown, A. Gavin, M. A. Kennard, and M. Stewart, "Breast cancer survivors' perceptions of complementary/alternative medicine (CAM): making the decision to use or not to use," Qualitative Health Research, vol. 9, no. 5, pp. 639653, 1999.

[7] H. Boon, M. Stewart, M. A. Kennard et al., "Use of complementary/alternative medicine by breast cancer survivors in Ontario: prevalence and perceptions," Journal of Clinical Oncology, vol. 18, no. 13, pp. 2515-2521, 2000.

[8] E. Rakovitch, J.-P. Pignol, C. Chartier et al., "Complementary and alternative medicine use is associated with an increased perception of breast cancer risk and death," Breast Cancer Research and Treatment, vol. 90, no. 2, pp. 139-148, 2005.

[9] C. Buettner, C. H. Kroenke, R. S. Phillips, R. B. Davis, D. M. Eisenberg, and M. D. Holmes, "Correlates of use of different types of complementary and alternative medicine by breast cancer survivors in the nurses' health study," Breast Cancer Research and Treatment, vol. 100, no. 2, pp. 219-227, 2006.
[10] Z. Chen, K. Gu, Y. Zheng, W. Zheng, W. Lu, and X. O. Shu, "The use of complementary and alternative medicine among Chinese women with breast cancer," The Journal of Alternative and Complementary Medicine, vol. 14, no. 8, pp. 1049-1055, 2008.

[11] H. Greenlee, M. L. Kwan, I. J. Ergas et al., "Complementary and alternative therapy use before and after breast cancer diagnosis: the Pathways Study," Breast Cancer Research and Treatment, vol. 117, no. 3, pp. 653-665, 2009.

[12] C. G. Pedersen, S. Christensen, A. B. Jensen, and R. Zachariae, "Prevalence, socio-demographic and clinical predictors of postdiagnostic utilisation of different types of complementary and alternative medicine (CAM) in a nationwide cohort of Danish women treated for primary breast cancer," European Journal of Cancer, vol. 45, no. 18, pp. 3172-3181, 2009.

[13] S. H. Shaharudin, S. Sulaiman, N. A. Emran, M. R. Shahril, and S. N. Hussain, "The use of complementary and alternative medicine among Malay breast cancer survivors," Alternative Therapies in Health and Medicine, vol. 17, no. 1, pp. 50-56, 2010.

[14] J. W. Henderson and R. J. Donatelle, "Complementary and alternative medicine use by women after completion of allopathic treatment for breast cancer," Alternative Therapies in Health and Medicine, vol. 10, no. 1, pp. 52-57, 2004.

[15] A. Wanchai, J. M. Armer, and B. R. Stewart, "Complementary and alternative medicine use among women with breast cancer: a systematic review," Clinical Journal of Oncology Nursing, vol. 14, no. 4, pp. E45-E55, 2010.

[16] K.-W. Jung, S. Park, H.-J. Kong et al., "Cancer statistics in Korea: incidence, mortality and survival in 2006-2007," Journal of Korean Medical Science, vol. 25, no. 8, pp. 1113-1121, 2010.

[17] J. I. Kang, N. Y. Sung, S. J. Park, C. G. Lee, and B. O. Lee, "The epidemiology of psychiatric disorders among women with breast cancer in South Korea: analysis of national registry data," Psycho-Oncology, vol. 23, no. 1, pp. 35-39, 2014.

[18] H. J. Chung, M. R. Kim, J. S. Bae et al., "Complementary and alternative medicine in patients with breast cancer," Journal of Breast Cancer, vol. 9, no. 4, p. 361, 2006.

[19] E. Kang, E. J. Yang, S.-M. Kim et al., "Complementary and alternative medicine use and assessment of quality of life in Korean breast cancer patients: a descriptive study," Supportive Care in Cancer, vol. 20, no. 3, pp. 461-473, 2012.

[20] E. Tautz, F. Momm, A. Hasenburg, and C. Guethlin, "Use of complementary and alternative medicine in breast cancer patients and their experiences: a cross-sectional study," European Journal of Cancer, vol. 48, no. 17, pp. 3133-3139, 2012.

[21] A. K. Matthews, S. A. Sellergren, D. Huo, M. List, and G. Fleming, "Complementary and alternative medicine use among breast cancer survivors," Journal of Alternative and Complementary Medicine, vol. 13, no. 5, pp. 555-562, 2007.

[22] S. M. Ock, J. Y. Choi, Y. S. Cha et al., "The use of complementary and alternative medicine in a general population in South Korea: results from a national survey in 2006," Journal of Korean Medical Science, vol. 24, no. 1, pp. 1-6, 2009.

[23] J. M. Bauml, S. Chokshi, M. M. Schapira et al., "Do attitudes and beliefs regarding complementary and alternative medicine impact its use among patients with cancer? A cross-sectional survey," Cancer, vol. 121, no. 14, pp. 2431-2438, 2015.

[24] P. A. Fasching, F. Thiel, K. Nicolaisen-Murmann et al., "Association of complementary methods with quality of life and life satisfaction in patients with gynecologic and breast malignancies," Supportive Care in Cancer, vol. 15, no. 11, pp. 1277-1284, 2007. 
[25] R. R. Love, H. Leventhal, D. V. Easterling, and D. R. Nerenz, "Side effects and emotional distress during cancer chemotherapy," Cancer, vol. 63, no. 3, pp. 604-612, 1989.

[26] E. Senkus-Konefka and J. Jassem, "Complications of breastcancer radiotherapy," Clinical Oncology, vol. 18, no. 3, pp. 229$235,2006$.

[27] N. Saibul, Z. M. Shariff, A. Rahmat, S. Sulaiman, and Y. H. Yaw, "Use of complementary and alternative medicine among breast cancer survivors," Asian Pacific Journal of Cancer Prevention, vol. 13, no. 8, pp. 4081-4086, 2012.

[28] C. A. Lengacher, M. P. Bennett, K. E. Kip, L. Gonzalez, P. Jacobsen, and C. E. Cox, "Relief of symptoms, side effects, and psychological distress through use of complementary and alternative medicine in women with breast cancer," Oncology Nursing Forum, vol. 33, no. 1, pp. 97-104, 2006.

[29] M. R. M. Visser and E. M. A. Smets, "Fatigue, depression and quality of life in cancer patients: how are they related?" Supportive Care in Cancer, vol. 6, no. 2, pp. 101-108, 1998.

[30] W. K. W. So, G. Marsh, W. M. Ling et al., "The symptom cluster of fatigue, pain, anxiety, and depression and the effect on the quality of life of women receiving treatment for breast cancer: a multicenter study," Oncology Nursing Forum, vol. 36, no. 4, pp. E205-E214, 2009.

[31] T. Kremser, A. Evans, A. Moore et al., "Use of complementary therapies by Australian women with breast cancer," The Breast, vol. 17, no. 4, pp. 387-394, 2008.

[32] M. S. Moran, S. Ma, R. Jagsi et al., "A prospective, multicenter study of complementary/alternative medicine (CAM) utilization during definitive radiation for breast cancer," International Journal of Radiation Oncology Biology Physics, vol. 85, no. 1, pp. 40-46, 2013.

[33] D. L. Stan, N. M. Collins, M. M. Olsen, I. Croghan, and S. Pruthi, "The evolution of mindfulness-based physical interventions in breast cancer survivors," Evidence-Based Complementary and Alternative Medicine, vol. 2012, Article ID 758641, 15 pages, 2012.

[34] M. R. Rao, N. Raghuram, H. R. Nagendra et al., "Anxiolytic effects of a yoga program in early breast cancer patients undergoing conventional treatment: a randomized controlled trial," Complementary Therapies in Medicine, vol. 17, no. 1, pp. $1-8,2009$.

[35] S. C. Danhauer, S. L. Mihalko, G. B. Russell et al., "Restorative yoga for women with breast cancer: finding from a randomized pilot study," Psycho-Oncology, vol. 18, no. 4, pp. 360-368, 2009.

[36] Y. Cui, X.-O. Shu, Y.-T. Gao, H. Cai, M.-H. Tao, and W. Zheng, "Association of ginseng use with survival and quality of life among breast cancer patients," American Journal of Epidemiology, vol. 163, no. 7, pp. 645-653, 2006.

[37] M. Markman, "Safety issues in using complementary and alternative medicine," Journal of Clinical Oncology, vol. 20, no. 18, supplement 1, pp. 39-41, 2002.

[38] J.-N. Lai, C.-T. Wu, and J.-D. Wang, "Prescription pattern of Chinese herbal products for breast cancer in Taiwan: a population-based study," Evidence-Based Complementary and Alternative Medicine, vol. 2012, Article ID 891893, 7 pages, 2012. 


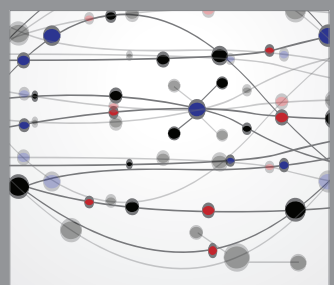

The Scientific World Journal
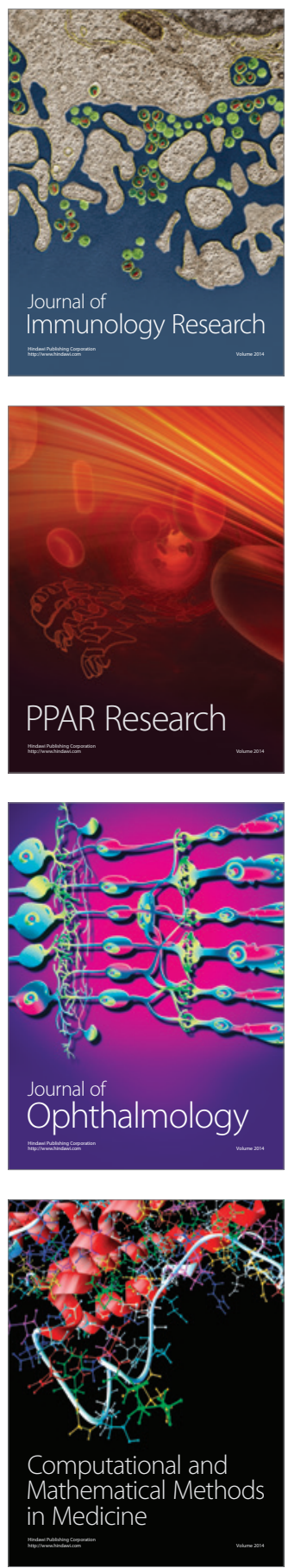

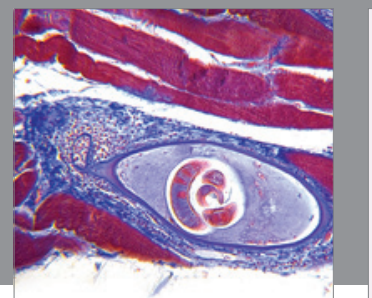

Gastroenterology

Research and Practice
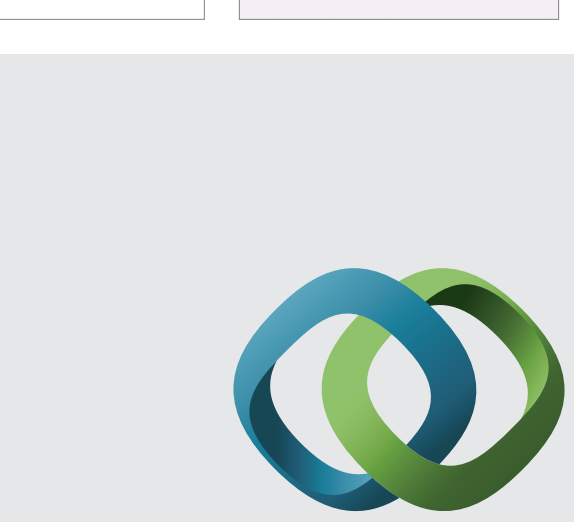

\section{Hindawi}

Submit your manuscripts at

http://www.hindawi.com
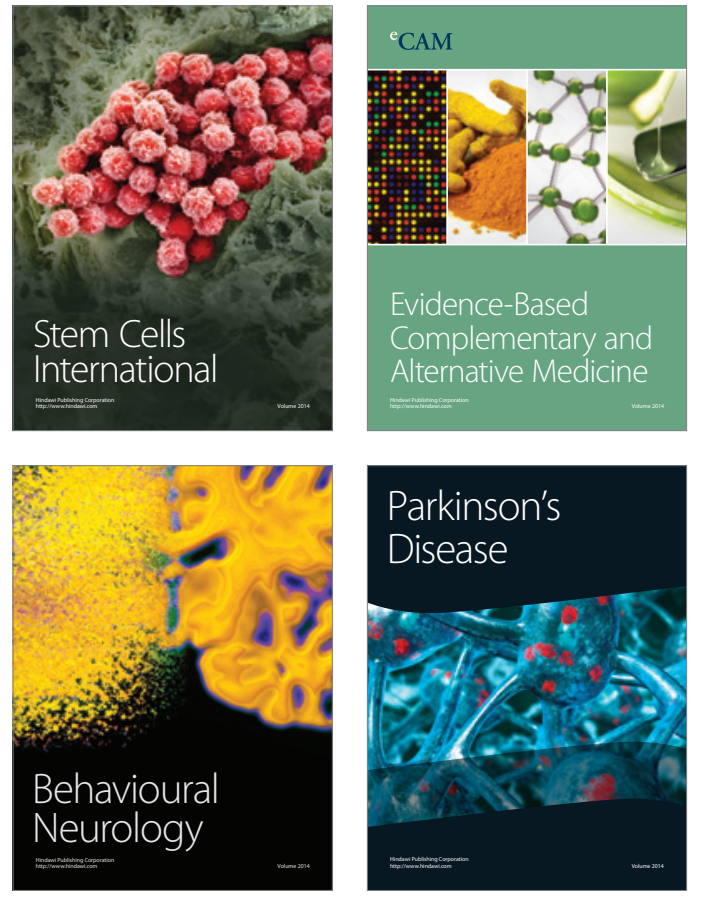
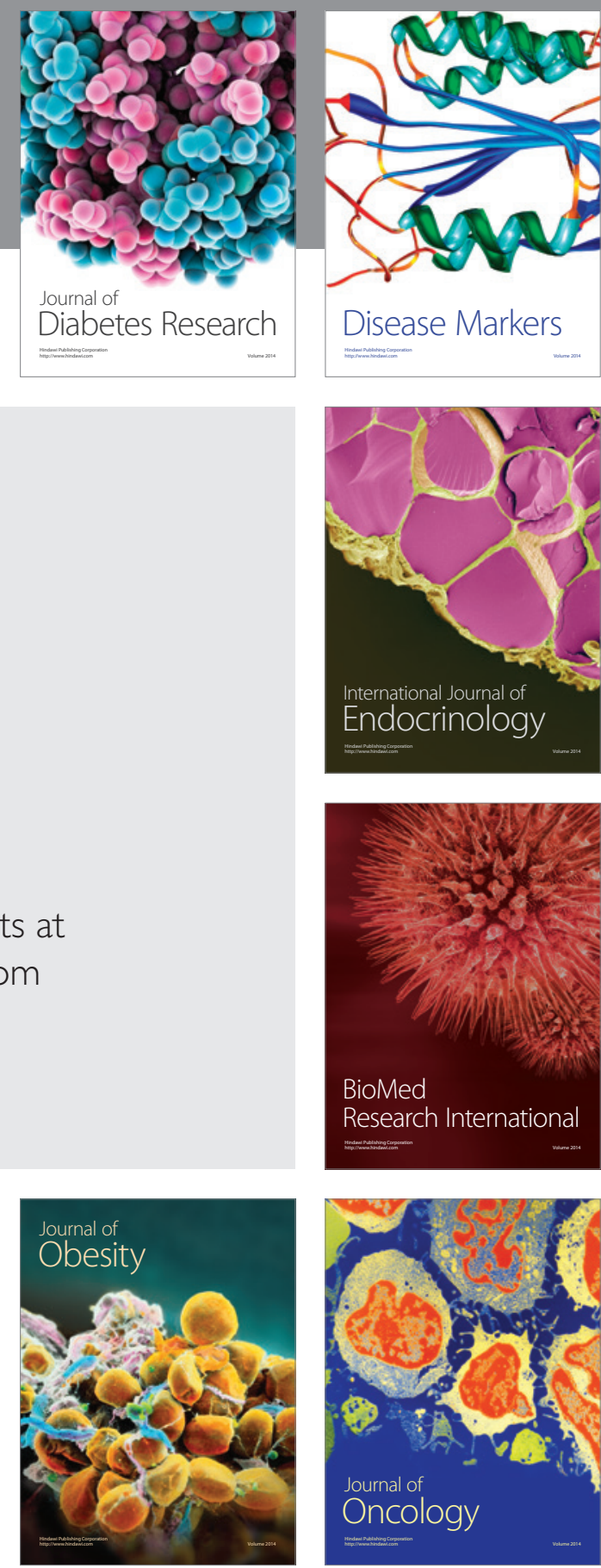

Disease Markers
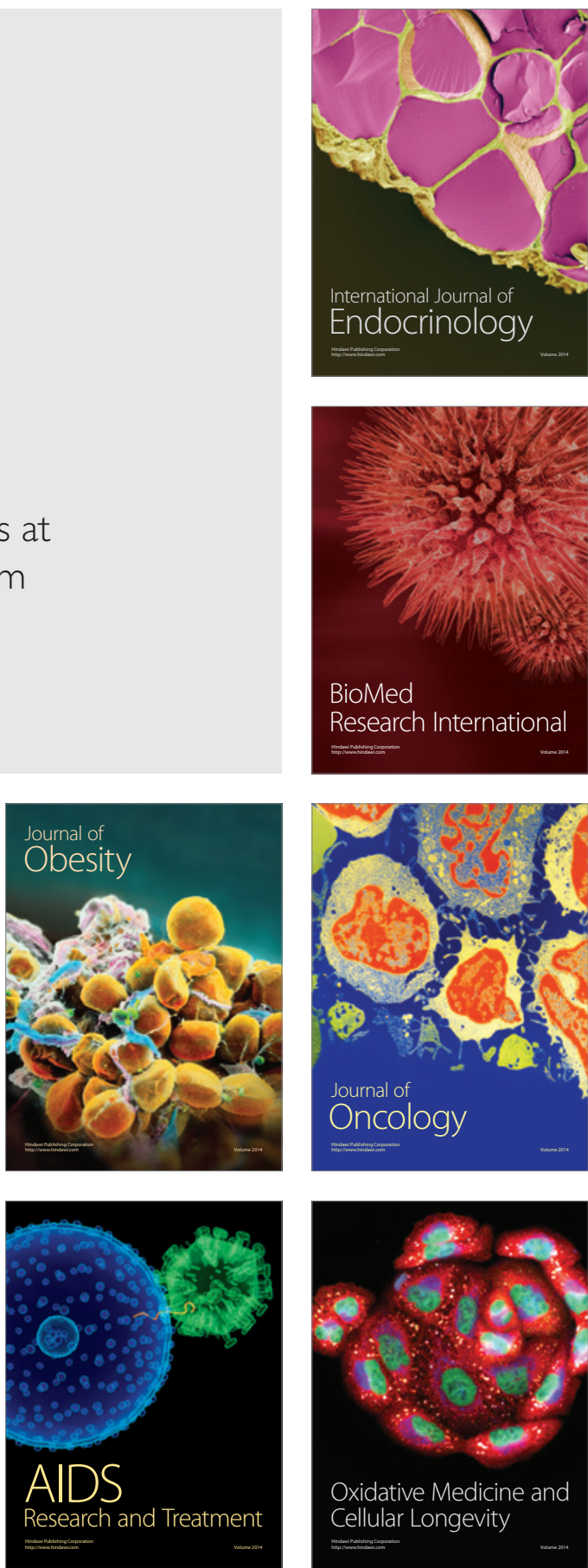